\title{
USING SAHRIS AWEB BASED APPLICATION FOR CREATING HERITAGE CASES AND PERMIT APPLICATIONS
}

\author{
N. Mlungwana \\ South African Heritage Resources Agency111 Harrington Street PO Box 4637, Cape Town 8000, South Africa \\ nmlungwana@sahra.org.za
}

KEY WORDS: Heritage Resources Managements, web-based, development applications, permits, SAHRIS

\begin{abstract}
:
Since the inception of the South African Heritage Resources Information System (SAHRIS) in 2012, creating heritage cases and permit applications has been streamlined, and interaction with South African Heritage Authorities has been simplified. SAHRIS facilitates applications for development cases and mining applications that trigger the South African National Heritage Resources Act (Act 25 of 1999) and is able to differentiate between cases that require comment only, where the heritage process is subsidiary to environmental or mining law (Section 38(8)), and those where the heritage authority is the deciding authority (Section 38(1)). The system further facilitates cases related to site and object management, as well as permit applications for excavation, invasive research techniques and export of materials for research abroad in the case of archaeological or palaeontological specimens, or for sale or exhibition in the case of heritage objects. The integrated, easy to use, online system has removed the need for applicants to print out forms, take documents from one government department to the next for approval and other time-consuming processes that accompany paper-based systems. SAHRIS is a user friendly application that makes it easy for applicants to make their submissions, but also allows applicants to track the progress of their cases with the relevant heritage authority, which allows for better response rates and turnaround times from the authorities, while also ensuring transparency and good governance practice.
\end{abstract}

\section{INTRODUCTION}

\subsection{Who is SAHRA?}

The South African Heritage Resources Agency (SAHRA) is a statutory organisation established under the National Heritage Resources Act (NHRA), No 25 of 1999 (South Africa, Dept. of Arts and Culture, 1999), as the national administrative body responsible for the protection of South Africa's cultural heritage (SAHRA, 2015a).

The NHRA follows stipulates that heritage resources should be managed at the most local level appropriate (South Africa, Dept. of Arts and Culture, 1999). This principle of devolution allows for the identification of three grades of heritage sites, National, Provincial and Local, each managed by the corresponding level of government. This means that, in addition to SAHRA, operating at a national level, there are Provincial Heritage Resources Authorities, which are responsible for heritage matters of provincial significance, and, once the process of devolution is completed, there will be heritage authorities at local, municipal level, managing sites of local importance.

In order to fulfil its mandate The South African Heritage Resources Agency (SAHRA) developed the South African Heritage Resources Information System, commonly known as SAHRIS. SAHRIS is the first online inventory system in South Africa for managing heritage resources. It is user friendly and interactive, and allows for a quick response time from authorities to applications. The responses and comments issued by authorities are visible on the case that the applicant has lodged; anyone who has access to the system can easily track the process that was followed to arrive at the relevant decision, ensuring transparency and good governance. All three tiers of heritage management, as prescribed in the NHRA, are accommodated on the system.



Figure 1: SAHRIS landing page at www.sahra.org.za/SAHRIS

\subsection{Structures of SAHRA}

Archaeological artefacts and sites, fossils and meteorites are protected by Section 35 of the NHRA (South Africa, Dept. of Arts and Culture, 1999). In terms of the legislation, no person may destroy, damage, alter, excavate, remove from its original site any archaeological material without a permit from the relevant heritage resources authority (South Africa, Dept. of Arts and Culture, 1999). This mandate is fulfilled by the SAHRA Archaeology, Palaeontology and Meteorites Unit (APM), which is made up of heritage specialists tasked with protecting these heritage resources. In terms of Section 38(8) of the NHRA, the APM Unit further provides comments on development and mining applications submitted in terms of 
South African environmental legislation where these activities could impact on heritage resources.

The NHRA allows archaeological sites to be declared as heritage sites so that they can be protected from destruction and damage. No person may destroy, damage, alter, excavate, or remove from its original site any archaeological material without a permit from the relevant heritage resources authority (South Africa, Dept. of Arts and Culture, 1999). The protection of archaeological and palaeontological sites and material and meteorites will become the responsibility of a Provincial Heritage Resources Authority (PHRA), once PHRAs are fully established and have been assessed by SAHRA as having the necessary competence. SAHRA will remain responsible for the export of such material until such time. (SAHRA, 2015c)

The Burial Grounds and Graves unit is mandated, in terms of Section 36 of the NHRA (South Africa, Dept. of Arts and Culture, 1999), to issue permits for any action regarding exhumation, repatriation and reburials of human remains. Further, SAHRA's policy regarding graves of conflict/liberation struggle, war graves and cemeteries is that they should not be altered, disturbed and relocated without a permit from SAHRA. Due to the sensitivity of these activities, heritage authorities have to make sure the necessary steps have been followed effectively before acting. SAHRA may not issue any permit in terms of Section 36 unless satisfied that concerted effort has been made to consult broadly with communities/interested individuals in such a grave. (SAHRA, 2015f)

Another SAHRA mandate, in terms of Section 32 of the NHRA (South Africa, Dept. of Arts and Culture, 1999), is the regulation of the movement of Heritage Objects that may be publicly or privately owned. Heritage Objects described on the Gazetted List of Types of Objects (No 24116, 6 December 2002) are assessed according to certain criteria described in Section 32 of the NHRA (South Africa, Dept. of Arts and Culture, 1999). If the objects meet the criteria, and form part of the National Estate, they are protected and may not be exported without a permit. (SAHRA, 2015g)

SAHRA's Maritime and Underwater Cultural Heritage (MUCH) Unit is tasked with protecting and managing South Africa's maritime and underwater cultural heritage, both along the South African coast, as well as in and around inland waters such as lakes, rivers and dams. This work includes site inspections and site monitoring, and is mandated in terms of Section 35(1) of the NHRA (South Africa, Dept. of Arts and Culture, 1999). The Unit processes applications for permits to conduct activities on shipwrecks sites or for activities that may affect maritime and/or underwater sites. In addition, it assesses and comments on Heritage Impact Assessments submitted as part of Environmental Impact Assessments that include possible impacts on maritime and underwater heritage, and are further available to answer queries from the public in relation to issues pertaining to these resources.

A permit is not required to visit most maritime and underwater cultural heritage sites, provided they are not disturbed or interfered with, and that no artefacts are removed or damaged. Permits to disturb shipwreck sites are generally only issued for activities which have a strong scientific basis, clear research questions, adequate funding, suitable provision for artefact conservation and curation, and will result in the generation of new knowledge about our maritime and underwater cultural heritage. (SAHRA, 2015h)
Through its Grading and Declaration Unit, SAHRA assists with the identification, assessment and conservation management planning of sites proposed for gazetting as National Heritage Sites, in terms of Sections 3, 7, 9 and 27 of the NHRA (South Africa, Dept. of Arts and Culture, 1999). This work contributes to the populating and expanding of the national inventory.

The process of grading and declaration includes consultation and public participation and culminates in the publishing of the National Heritage Site (NHS) status of the site in the Government Gazette. The Grading and Declarations Unit provides a service to several other units within the Heritage Resources Management department of SAHRA and collaborates with the officers of those units to ensure the efficient and timeous declaration of such diverse resources as sites, objects, shipwrecks and graves. (SAHRA, 2015i)

\subsection{SAHRIS as the National Inventory}

In terms of the Section 39 of the NHRA, SAHRA is required to compile and maintain an inventory of the national estate, defined as heritage resources of cultural significance (South Africa, Dept. of Arts and Culture, 1999). This inventory must be in the form of a database of information on heritage resources and may include: all places and objects protected through the publication of notices in the Gazette or Provincial Gazette, whether in terms of this Act or provincial legislation; places and objects subject to general protections in terms of this Act or provincial legislation for the management of heritage resources; and any other place and object which it considers to be of heritage significance; and all places and objects with which it and its predecessors have been involved (South Africa, Dept. of Arts and Culture, 1999). As such, SAHRIS fulfils this role. (SAHRA, 2015d)

\section{CREATING APPLICATIONS ON SAHRIS}

\subsection{Applications on SAHRIS}

The purpose of the NHRA is to protect those heritage resources of South Africa which are of cultural significance or other special value for the present community and for future generations because they are considered part of the national estate and fall within the sphere of operations of heritage resources authorities (South Africa, Dept. of Arts and Culture, 1999). SAHRA achieves this by participating in the various processes that serve to manage heritage resources in the country. (SAHRA, 2015e)

SAHRIS has made it easy for applicants and heritage authorities to interact through the submission of applications via a 4 page online wizard that allows users to fill out all relevant details about their project, through a quick, easily followed process. The kind of application is specified, i.e. a permit for site management or export of heritage objects; applications for developments or mining rights; reporting heritage crimes, and nominations, declarations and provisional protection of heritage sites. This allows the case to be channelled to the correct branch of the appropriate heritage authority.

The coordinates of sites created on SAHRIS are mapped using the system's built in GIS functionality, as are the locations of heritage objects within repositories such as museums and galleries. The sites and objects are protected by setting their viewing rights to private, making them visible only to those that have the authority do so. 


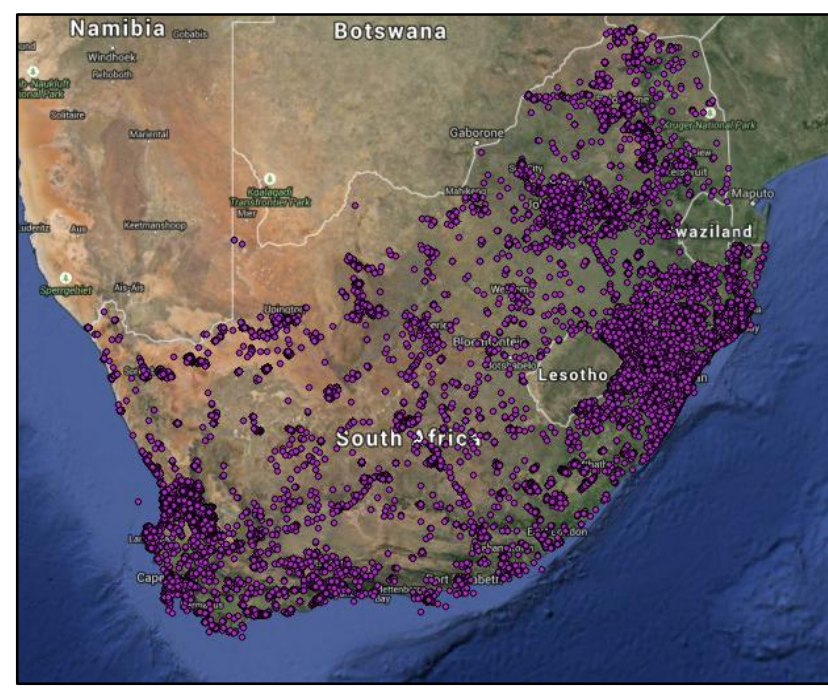

Figure 2: Non-specific site location map

The authority to view potentially sensitive site or object data is managed through the creation of Organic Groups (OG), which consist of the applicant, the relevant, assigned heritage officers and any other appropriate people who are added to the OG by the applicant. Once the sites or objects are on the system it is possible to attach them to the permit application related to them. The system performs auto searches of existing content and will populate the site or object field in the wizard as the applicant types the name in.

\subsubsection{Permit Applications}

Section 35(4) of the NHRA (South Africa, Dept. of Arts and Culture, 1999) states that: (a) No person may, without a permit issued by the responsible heritage resources authority: (b) destroy, damage, excavate, alter, deface or otherwise disturb any archaeological or palaeontological site or any meteorite; (c) destroy, damage, excavate, remove from its original position, collect or own any archaeological or palaeontological material or object or any meteorite; (d) trade in, sell for private gain, export or attempt to export from the Republic any category of archaeological or palaeontological material or object, or any meteorite; or (e) bring onto or use at an archaeological or palaeontological site any excavation equipment or any equipment which assist in the detection or recovery of metals or archaeological and palaeontological material or objects, or use such equipment for the recovery of meteorites. Anyone found guilty of an offence in terms of the Act is liable for a fine or imprisonment, or both. In cases where material is accidentally disturbed by mining, engineering or agricultural activities, the finds must be reported to a cultural institution such as a museum or university department, or the South African Heritage Resources Agency.

Permits are generally issued for: the export of material; research excavation; mitigation excavation that form part of development applications, in terms of Section 38; and for the filming of (or at) archaeological and palaeontological sites. Permits are only issued for bona fide research purposes and to suitably qualified professionals, however, any individual may apply to SAHRA for a permit. Fees payable to process permit applications are gazetted in the Government Gazette (No. 669, July 2005) (SAHRA, 2015c).

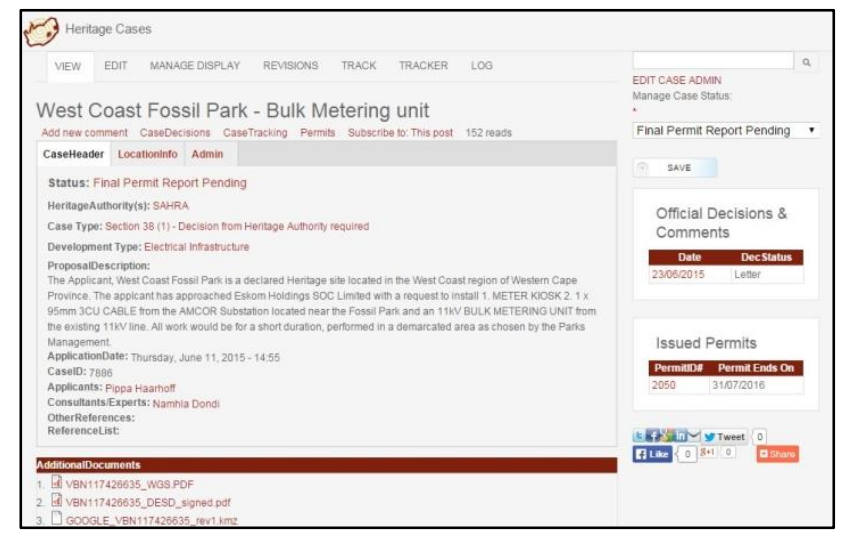

Figure 3: Example of a permit application on SAHRIS

Once an applicant has filled in the online application and attached all the necessary documents, they change the case status from "Draft" to "Submitted" to indicate that the application is complete and ready for assessment by a heritage officer, who will then comment on the application or issue the permit. The comment or the permit issued to the applicant is then visible immediately to the applicant, attached to the case created by the applicant.

In the process of permit application there is a field to populate objects or sites. If the objects or sites are already saved on the system you can easily search for them, if not, you have an option to create the object or site. Once the application has been submitted on SAHRIS, it will usually take 3-5 days for an application to be processed. Permits are issued at minimal fee and under certain conditions. The permit holder must be a professionally trained specialist in the appropriate field, for instance archaeology or palaeontology, or must be supervised by such a person.

Proper records must be kept of the excavation or collecting programme; all material recovered must be placed in a public institution where it is available to anyone for study and the application form must be signed by the Director of a museum or a university department agreeing to curate and store the material; regular annual reports must be submitted to SAHRA, as well as a final report and copies of all publications and theses relating to the study; all excavations must be filled in after the work has been completed; and it is the duty of the permit holder to obtain permission from the land owner for access to a site.

\subsubsection{Development and Mining Applications}

Development and mining applications are governed by Section 38 of the NHRA, and the bulk of the work handled by the heritage authorities is generated by Section 38(8) (South Africa, Dept. of Arts and Culture, 1999). This section pertains to applications made in terms of broader legislation, such as environmental or mining law, that has possible implications for heritage resources.

In terms of this section, and in order to ensure the protection of heritage resources, heritage authority input is required as part of the Environmental Impact Assessment process of the National Environmental Management Act, Number 107 of 1998 (South Africa, Dept. of Environmental Affairs, 1998) for certain types of development and mining applications. This legislation requires that consideration is made of potential impacts to heritage resources prior to the environmental or mining state 
authorities issuing approval of applications for development or mining permits.

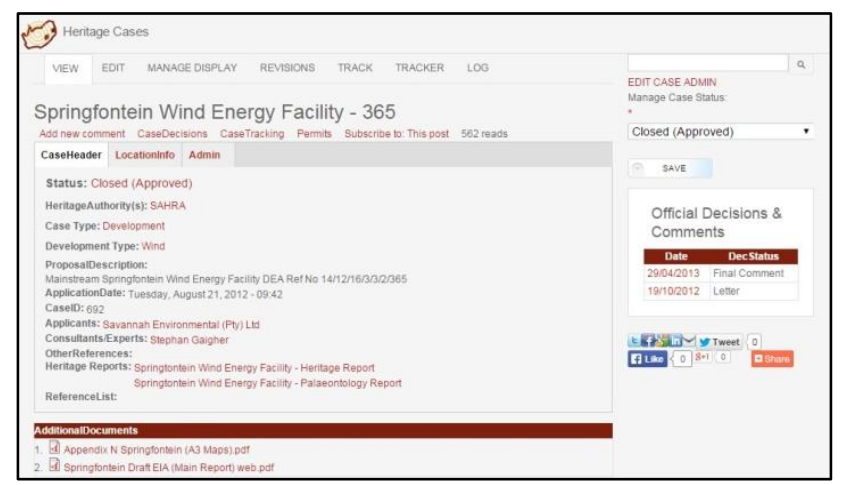

Figure 4: Example of a development application on SAHRIS

SAHRIS allows for these composite Environmental Impact Assessment documents and reports to be appended to the applications, thus allowing applicants to submit all the relevant and required information to a single platform. This enables the heritage authority to make an informed decision in a short space of time, based on a comprehensive body of evidence related to all aspects of the application in addition to the heritage component. These documents include but are not limited to Background Information Documents, Basic Assessment Reports, Scoping Assessments, Environmental Impact Assessments and Environmental Management Plans. These are submitted in addition to the heritage reports, which include Palaeontological Impact Assessments, Archaeological Impact Assessments and Heritage Impact Assessments. Significantly, SAHRIS' built in GIS allows for these applications to be mapped as polygons, creating composite development maps for the country.

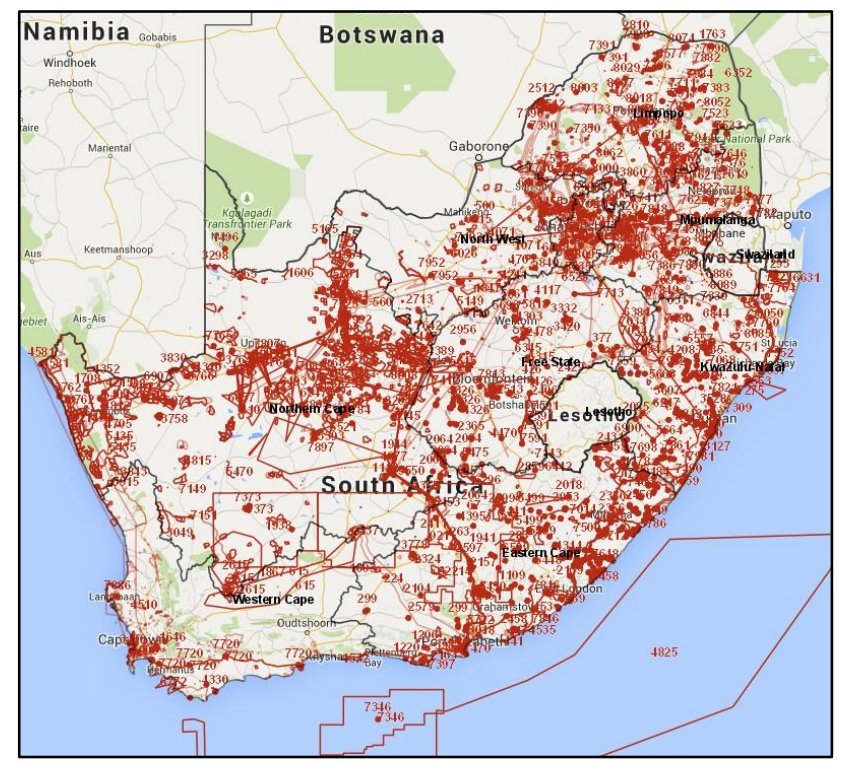

Figure 5: Development application map on SAHRIS

\section{OVERVIEW OF ACTIVITY PER PROVINCE}

SAHRIS is currently ranked within the top one million most visited sites in the world, and ranks within the top 5000 sites in South Africa (Alexa Internet, 2015). There are, to date, 7235 cases that have been lodged on SAHRIS, with 1807 being permit applications. These are the figures broken into the 9 Provinces of South Africa with KwaZulu Natal at 1366 applications, Gauteng at 194, Free State 80, Limpopo 77, Northern Cape 993, North West 150, Mpumalanga 135, Eastern Cape 468 and Western Cape at 99. With these figures it is evident that a lot of activity occurs in KwaZulu Natal, which is due to the presence of a high functioning Provincial Heritage Resources Authority in this province.

\section{CONCLUSION}

From the above, we can see that SAHRIS has effectively facilitated the move from a paper-based application system to a paperless environment. Only a few steps are required to complete an application, which provides all the information that is relevant to the application and makes it easier for the heritage authorities to effectively make an informed decision. SAHRIS also offers a secure environment that protects sensitive data such as personal information or sensitive information related to potentially vulnerable heritage resources, which are protected in fields that are not visible to the public, but are only accessible to the applicant and the heritage officer. Interacting with Heritage authorities is possible in real time through built in instant messaging systems and access to case decisions and comments as they are generated, which allows for better response rates and turnaround times from the authorities. 


\section{REFERENCES}
Alexa
Internet,
2015.
SAHRA.org.za, http://www.alexa.com/siteinfo/sahra.org.za (5 July 2015).

Department of Arts and Culture, South Africa, 1999. National Heritage Resources Act 25 of 1999. Government Gazette, 506(19974), Pretoria, Government Printers, 28 April http://www.sahra.org.za/legislations/ (5 July 2015).

Department of Environmental Affairs, South Africa, 1998. National Environmental Management Act 107 of 1998. Government Gazette, 1450(19519), Pretoria, Government Printers, 27 November http://www.sahra.org.za/legislations/ (5 July 2015).

SAHRA, 2015a. News $l^{\text {st }}$ edition 2015/16. SAHRA http://www.sahra.org.za/newsletters/ (6 July 2015)

SAHRA, 2015b. Information booklet. SAHRA http://www.sahra.org.za/information-booklets/ (7 July 2015).
SAHRA, 2015c. Archaeology, Palaeontology and Meteorites. SAHRA http://www.sahra.org.za/apm/SAHRA (7 July 2015).

SAHRA, 2015d. National Inventory. SAHRA http://www.sahra.org.za/national-inventory/ (7July 2015)

SAHRA, 2015e. Built Environment. SAHRA http://www.sahra.org.za/built-environment/ (7July 2015)

SAHRA, 2015f. Burial Grounds and Graves. SAHRA http://www.sahra.org.za/burial-grounds-and-graves/ (7July 2015)

SAHRA, 2015g. Heritage Objects. SAHRA http://www.sahra.org.za/heritage-objects/ (8July 2015)

SAHRA, 2015h. Maritime and Underwater Cultural Heritage. SAHRA http://www.sahra.org.za/maritime-underwatercultural-heritage-2// (8July 2015)

SAHRA, 2015i. Grading and Declarations. SAHRA http://www.sahra.org.za/grading/ (8July 2015) 